Artigos 


\section{Metáfora e discurso filosófico}

\section{Metaphor and philosophical speech}

Prof. ${ }^{a}$ Dr. ${ }^{a}$ Rita de Cássia Oliveira rcoliveira30@yahoo.com.br

Universidade Federal do Maranhão

A investigação de Ricoeur do uso da metáfora no discurso filosófico conduz o discurso a um centro de gravidade que se assenta no plano da hermenêutica por deslocar os pressupostos da retórica para a semântica e os problemas de sentido para os problemas de referência, o que faz emergir sob a forma de postulados um determinado número de pressupostos do discurso filosófico. $\mathrm{O}$ plano da hermenêutica se torna fundamental devido à possibilitar a elevação da linguagem no seu sentido autônomo, privilegiando o primado da subjetividade por explicitar o mundo que o discurso filosófico descobre e abre, tematizando sobre seu referente e seu valor de verdade.

PALAVRAS-CHAVE

Metáfora. Discurso filosófico. Retórica.

Semântica. Significação. Locução.

The investigation of Paul Ricoeur about the use of metaphor in the philosophical speech transports the speech to a centre of gravity which is founded on the plan of Hermeneutics, because Hermeneutics moves the bases of Rhetoric to Semantics and the problems of meaning to the problems of reference, what makes to emerge under the form of assumptions a certain number of bases of the philosophical speech. The plan of Hermeneutics becomes fundamental due to make possible the elevation of language in its autonomous meaning, favoring the primacy of subjectivity to explain the world which the philosophical speech discovers and opens, speaking about its reference and its value of truth

\section{$\begin{array}{ll}\text { KEY-WORDS } & \text { Metaphor. Philosophical Speech. } \\ \text { Rhetoric. Semantics. Meaning }\end{array}$}




\section{Introdução}

A passagem da retórica para a semântica viabiliza um tratamento que considera o deslocamento da metáfora da palavra, mais precisamente atribuída ao nome, na teoria da significação, para a frase, sendo esta considerada como primeira unidade de significação. A metáfora atribuída ao nome é concebida como um tropo, por ser um desvio que afeta a significação da palavra. Na teoria aristotélica, a metáfora possui dupla função: poética e retórica, localizando-se na quarta parte da léxis ${ }^{1}$, isto é, no nome, que é definido como um som completo dotado de significação.

O domínio da palavra na teoria da significação é apontado como um erro categorial que leva ao declínio da retórica, segundo Ricoeur, devido à metáfora ser reduzida a um simples ornamento. Daí resulta que a teoria inicial da significação primou como seu centro a denominação, interferindo na arte da persuasão como um discurso que valoriza a palavra ornamentada por se tratar de uma elocução fundamentada na teoria dos tropos. Essa teoria se baseia na premissa de que certos nomes pertencem às coisas como próprios, conferindo-lhes o sentido próprio, quando falta esse termo quer por ausência, quer por uma escolha de caráter estilístico, recorre-se a um recurso de uso de um termo impróprio para preencher a lacuna lexical, daí se usa um termo impróprio ou figurado para substituir a palavra ausente Esse termo utilizado é a metáfora que tanto por ausência como por opção estilística ornamenta o discurso sem proporcionar uma verdade, o que implica na falta de qualquer informação nova, ou seja, a metáfora não ensina e tem uma função somente decorativa, tornando a Retórica um discurso belo, mas vazio de sentido e sem referência. Mas, pergunta-se: o que é o sentido próprio de uma palavra? Ricoeur coloca que para Richards, as palavras não têm sentido próprio porque não têm significação como própria na medida em que não possuem sentido em si mesmas. E o discurso é que contém o sentido de modo uno, na medida em que o contexto do discurso é em si mesmo, por fazer parte de um contexto maior, formado pela situação de pergunta e de resposta, o que significa que as palavras detém o seu sentido somente devido a um fenômeno de "eficácia delegada"2.

\footnotetext{
1 A elocução (léxis) ou as formas elocucionárias do discurso, referem-se às seguintes partes: a letra, a sílaba, a conjunção, o nome, o verbo, o artigo, a flexão e a proposição. A letra, sendo um som indivisível e a primeira parte da elocução, provém da métrica. A sílaba é um som desprovido de significação própria, a conjunção é palavra destituída de significado próprio, mas que não obsta nem contribui para que vários sons significativos componham uma única expressão significativa: logo, por oposição a esta falta de representação e o nome é definido como um som completo dotado de significação: já o verbo é som significativo que exprime o tempo e cujas partes, como as do nome, fora do conjunto, não tem significado nenhum. A relação do nome com o verbo constituirá a flexão que será complexada na proposição que se define como um som complexo com significação complexa, cujas múltiplas partes possuem um sentido por si mesmas.
}

2 A eficácia delegada é a troca de significados das palavras que forma um contexto, porque nós somos coisa que respondem a outras coisas. 
"Um contexto é um nome de um feixe de acontecimentos que surgem conjuntamente, incluindo aí as condições requeridas assim como o que podemos isolar como causa ou efeito" (RICOEUR apud RICHARDS, 1988, p. 121).

Ricoeur percebe que Richards aponta para uma semântica da metáfora por apoiar-se na tese da interanimação das palavras no enunciado, que restitui as possibilidades interpretativas das palavras contidas no todo do discurso. Com isso, a metáfora tem validade para todas as formas de duplo sentido, podendo ser ligada às intenções, às pressuposições e às convenções veiculadas pelas partes ausentes do contexto. Assim, a frase tem prioridade em relação às palavras e estas não se constituem como nomes das ideias presentes no espírito, elas limitam-se a reenviar sentido para as partes ausentes do contexto do enunciado.

O enunciado metafórico não revoga a definição nominal da metáfora, uma vez que a palavra continua como a portadora do efeito de sentido metafórico, devido a isso permanece a definição de Aristóteles sobre a metáfora como "o transporte para uma coisa do nome de outra, ou do gênero para a espécie, ou da espécie para o gênero, ou da espécie de uma para a espécie de outra, ou por analogia” (ARISTÓTELES, 1987, p.220).“

Mas, ocorre que a palavra quando transporta a metáfora, o seu efeito de sentido reverbera em todo o enunciado porque a sua primeira unidade é a frase. O que é a frase? De acordo com Ricoeur, o linguista francês Benveniste define a frase como sendo uma unidade de nível superior que se realiza em palavras constituindo um todo que não se reduz à soma de suas partes, porém, o sentido inerente deste todo é repartido pelo conjunto dos constituintes. Assim, com a frase adentramos em um novo domínio linguístico: o discurso.

O discurso, dir-se-á, que é produzido cada vez que se fala, esta manifestação da enunciação, não é simplesmente a "fala"? - É preciso ter cuidado com a condição específica da enunciação: é o ato mesmo de produzir um enunciado, e não o texto do enunciado, que é nosso objeto. Este ato é o fato do locutor que mobiliza a língua por sua conta. A relação do locutor com a língua determina os caracteres linguísticos da enunciação. Deve-se considerá-la como o fato do locutor, que toma a língua por instrumento, e nos caracteres linguísticos que marcam esta relação (BENVENISTE, 1989, p. 82). 
Benveniste sublinha que qualquer discurso produz-se como um acontecimento por se caracterizar em "atos discretos e de cada vez únicos pelos quais a língua se atualiza em falas por um locutor; daí a expressão "instância do discurso", forjada pelo linguista para opor o discurso à língua devido a esta ter na sucessão do tempo somente uma existência virtual na medida em que ela existe propriamente quando um locutor dela se apropria e a atualiza. E o discurso que como acontecimento é transitório e fugaz, como fica a sua existência? A essa questão, Benveniste explica que o discurso pode ser identificado e reidentificado através da expressão "mesmo" que introduz a sua significação como a identificação de princípio de toda e qualquer unidade de discurso, impondo um sentido. Portanto, a instância do discurso é mister um acontecimento repetível.

\section{Função identificante e função predicativa no discurso filosófico}

O discurso apresenta uma polaridade típica: função identificante e função predicativa, caracterizando-se pelo enlaço do nome e do verbo para formar o logos articulado, devido ao entrelaçamento do discurso visar alguma coisa, podendo ser apreciado enquanto verdadeiro ou falso. Essa polaridade entre identificante e função predicativa se apresenta por um lado nos individuais denominados que são seres que existem, mesmo que essa existência seja neutralizada, como é o caso da ficção: sempre se fala de qualquer coisa que é, porque a noção de existência está ligada à função singularizante da linguagem, ora, os sujeitos logicamente próprios são em potencial existentes, daí a "aderência" da linguagem às coisas. Por outro lado, na predicação de qualidade temos as classes, relações e ações que são de fato universais, porque ela diz respeito ao inexistente, daí não fazer sentido perguntar se a felicidade existe, mas se um tal que é feliz, existe. Segundo Ricoeur, a dissimetria das duas funções implica portanto também na dissimetria ontológica do sujeito e do predicado.

$\mathrm{Na}$ estrutura dos atos de discurso podem se considerar três aspectos: locução, ilocução e perlocução, sendo que Ricouer não se reporta ao último ato por nós referendado e que consta na Teoria dos Atos de Fala elaborada por Austin. O primeiro, a locução, refere-se ao proferimento de uma sentença com um certo significado; o segundo, a ação ilocutória, constitui-se num proferimento de louvor, ameaça, crítica, anuência, etc. Em terceiro, a ação perlocutória se configura no efeito que o locutor deseja obter da audiência em consequência do proferi- 
mento. Assim, todos os atos de discurso compreendem simultaneamente essas três ações porque se faz referência da função identificante à função predicativa.

É somente na frase que se pode encontrar a distinção entre sentido e referência feita por Frege, que reconheceu que é na frase que se pode distinguir o que é dito daquilo que se diz. Pode-se evidenciar a diferença entre sentido e referência na simples definição equacional: $A=B$, em que $A$ e $B$ têm sentidos diferentes; mas se se confere sentidos iguais diz-se que ambos se referem à mesma coisa, podendo ainda haver dois sentidos para a mesma referência ou aqueles casos em que não existe referente assinalável empiricamente. Essa distinção entre sentido e referência é absolutamente característico do discurso. A referência pode ser à realidade e ao locutor por tratar-se de um fenômeno dialético. Em decorrência do discurso refere-se à uma situação, à uma experiência, à uma realidade, ao mundo, em suma, ao extralinguístico, "refere-se também ao seu próprio locutor por processos que são essencialmente de discurso e não de língua" (RICOEUR, 1988, p. 117). Esse processo dialético tem o seu ponto inicial com os pronomes pessoais por serem "assémicos": a palavra "eu" não possui em si mesma significação, é um indicador de discurso daquele que fala, por isso só tem sentido quando alguém fala e se designa a si mesmo ao dizer “eu”. Juntam-se aos pronomes pessoais os tempos dos verbos por constituírem-se em sistemas gramaticais muito diferentes, porém, têm um ponto fixo no presente, que é o próprio momento em que o discurso é pronunciado, uma vez que o discurso qualifica-se a si próprio temporalmente. Os advérbios e os demonstrativos possuem essa mesma característica temporal, com isso o caráter autorreferencial está implícito na própria noção de instância do discurso.

O último traço considerável nas características do discurso é a distinção entre o semiótico e o semântico, que se encontra na separação do paradigmático e do sintagmático. Comecemos a notificar que o paradigma é semiótico e a ele pertencem as flexões, as derivações e os signos no sistema. Ao sintagma pertence o próprio nome que possibilita se alcançar o sentido da frase. Daí, a substituição fazer parte da lei sintagmática, tendo que ser colocada ao lado da semântica, com isso se percebe que a metáfora tratada em termos de discurso por ser o "enunciado metafórico", é um sintagma. Essa condição nos leva a classificar a metáfora como semântica por afetar o sentido entre as substituições, o que requer uma investigação semântica porque visa a forma do discurso, logo, do sintagma, realizado pela metáfora. Assim, é como sintagma que o enunciado metafórico deve ser considerado devido ao "efeito de sentido resultar de uma determinada ação que as palavras exercem umas sobre as outras na frase" (RICOEUR, 1988, p. 118). 
As palavras não possuem significação própria em razão de não terem sentido em si mesmas, uma vez que é o discurso tomado como um todo que carrega o sentido de modo indivisível. Restabelece-se os direitos do discurso às expensas dos direitos das palavras. Daí, segundo Ricoeur, é que Richards pode edificar a sua lei do contexto:

E, em primeiro lugar, o fato da troca que impõe o primado do contexto: "Nós somos coisas que respondem as outras coisas"; o contexto do discurso é portanto, em si mesmo, uma parte de um contexto mais vasto, constituído pela situação de pergunta e de resposta. Por outro lado, num naco de discurso, as palavras devem o seu sentido apenas a um fenômeno de eficácia delegada (RICOEUR apud RICHARDS, 1988, p. 120-121).

Com isso, Richards quer dizer que as palavras têm significação apenas por abreviação do contexto, porque exprimem a sua significação segundo as partes ausentes de contextos dos quais retiram a sua eficácia delegada.

As palavras não são os nomes das ideias presentes nos nossos espíritos, pois não há uma associação fixa entre elas e o que as constitui, apenas elas limitam-se a reenviar para as partes ausentes do contexto. Logo, a constância de sentido é somente a constância dos contextos. Portanto, não há oposição a que uma palavra signifique mais do que uma outra, o que nos faz lembrar a teoria do valor de Saussure que prega que "Os valores correspondem a conceitos, subtendo-se que são puramente diferenciados, definidos não positivamente por seu conteúdo, mas negativamente por suas relações com outros termos do sistema. Sua característica mais exata é ser o que os outros não são" (SAUSSURE, 1075, p. 136).

A teoria do valor enaltece o primado da palavra e estabelece que as unidades características dos diversos níveis de organização da linguagem derivariam de uma única ciência: a semiótica, segundo Ricoeur, a preocupação dominante de Saussure foi identificar, definir, delimitar a unidade linguística de base, isto é, o signo.

Para Ricoeur, as palavras exprimem pela sua sobredeterminação das "rivalidades de grande escala entre contextos". O filósofo assegura que essa crítica da superstição da única significação verdadeira possibilita uma consideração positiva do papel da metáfora como, também, 
de todas as formas de duplo-sentido que podem ser ligadas às intenções, às pressuposições e às convenções veiculadas pelas partes ausentes do contexto. A metáfora diz respeito à própria profundidade da interação verbal, resultante numa onipresença do "teorema contextual da significação"? Ricoeur diz que o princípio da metáfora deriva da constituição das palavras, quando se concebe a palavra como substituto de uma combinação de aspectos em que essa combinação é a parte ausente dos diversos contextos e de acordo com uma formulação elementar a metáfora mantém dois pensamentos de coisas simultaneamente no meio de uma palavra ou de uma expressão simples cuja significação resulta da sua interação:"Ou, para harmonizar esta descrição com o teorema da significação, veremos que a metáfora mantém conjuntamente numa significação simples duas partes ausentes diferentes dos contextos diferentes desta significação" (RICOUER, 1988, p. 125).

Daí, Ricoeur dizer que a metáfora é uma habilidade, um talento de pensamento, sendo, então, a retórica, a reflexão e a tradução desse talento num saber distintivo.

Há metáfora no discurso filosófico? Até que ponto? É essencial? Acidental? Para respondermos a tais questões se faz necessário introduzir uma discussão sobre a univocidade e a equivocidade para podermos esclarecer se o discurso filosófico pode reproduzir no seu plano o funcionamento semântico do discurso poético. Para tanto, esclarecemos que a palavra analogia parece fazer parte dos dois domínios: do lado da poética, a analogia tem o sentido de proporção, pertencendo à quarta espécie de metáfora ${ }^{3}$, a que Aristóteles no livro Tratado das Categorias onde elabora um modelo de analogia que não corresponde ao poético e produz uma teoria não metafórica da analogia para corresponder ao discurso especulativo presente na Metafisica através de uma questão que rompe tanto com o discurso poético quanto com o discurso ordinário: o que é o ser?

Essa questão remete o filósofo, de modo geral, ao paradoxo de que o ser se diz de várias maneiras. Essa multiplicidade de significações do ser só é possível devido à relação de reenvio a um termo primeiro, que não constitui nem a univocidade de um gênero, nem a univocidade do uso de uma simples palavra,

3 "Digo que há analogia quando o segundo termo está para o primeiro na igual relação $\mathrm{cm}$ que está o quarto para o terceiro, porque, neste caso. o quarto termo poderá substituir o segundo, e o segundo o quarto" (ARISTÓTELES, 1987, p. 221). 
segundo Ricoeur (1988, p.387), "a plurivocidade que assim leva ao discurso filosófico é de ordem diferente da do sentido múltiplo produzido pela enunciação metafórica". Essa plurivocidade pertence à questão que abriu o campo especulativo por ser da sua mesma ordem. É assim que o termo ousia coloca no mesmo plano todos os outros termos usados no sentido recortado pela questão: o que é o ser? Para responder a essa questão, os filósofos usam termos que podem ou não estar numa relação da analogia, porque o que importa é a identificação entre as significações múltiplas do termo ser que, sem proceder da divisão de um gênero em espécie constituirá uma ordem de categorias devido a ser a condição de possibilidade da extensão ordenada do campo dos predicados. Portanto, a polissemia é controlada no uso da função predicativa do termo ser: "O discurso filosófico instaura-se como guarda vigilante das extensões de sentido controladas sobre o fundo das quais se destacam as extensões inéditas do sentido do discurso poético" (RICOEUR, 1988, p. 388).

Essa distinção diz respeito mais às coisas nomeadas do que às significações. Porém, a distinção decisiva em Aristóteles, presente no Tratado das Categorias, conforme Ricoeur na Metáfora Viva, é aquela que opõe e combina os dois sentidos da cópula "é", a saber: ser - dito de; e, ser - em. Toda a sequência do Tratado dá, a partir dessa distinção, um emprego à distinção seguinte entre os sinônimos e os parônimos. Observa-se que a atribuição sinonímica ocorre apenas pela relação dito-de. Os dois sentidos da cópula ser-dito de e ser-em são opostos e combinados, podendo-se compor numa tábua de ausência e de presença quatro classes de substantivos: dois concretos (Sócrates, homem) e dois abstratos (tal branco, a ciência). Assim, a morfologia aristotélica edifica-se sobre o cruzamento de duas oposições fundamentais: a oposição do particular e do geral, que torna possível a predicação propriamente dita (ser dito de...) e a do concreto e do abstrato (que torna possível a predicação no sentido estrito). A primeira, a predicação em sentido geral, entendida num sentido realista, consagra que a cópula não se reduz a uma obscuridade quando ligada à materialidade das substâncias individuais (O homem é mortal). A segunda, entendida no sentido conceitualista, pode tomar o lugar da pretensa participação das ideias platônicas, que Aristóteles denuncia como sendo metafóricas.

\section{A analogia e a aporia das acepções múltiplas do ser}

Ricoeur pergunta: "Como é que a analogia é posta em jogo, senão explicitamente (uma vez que a palavra não é pronunciada), pelo menos implicitamente?" Segundo o filósofo francês, isso ocorre sim, quando as modalidades sintáticas 
da cópula ao diversificarem-se enfraquecem continuamente o sentido da cópula afastando-se da predicação essencial primordial - ser-dito de..., a única que tem sentido sinonímico; para dirigir-se à predicação acidental derivada: ser-em... Daí ocorre uma diferença entre o Tratado das Categorias e da Metafísica $\Gamma$. $\mathrm{O}$ primeiro estuda a morfologia e a predicação. O segundo, trata do reenvio de todas a categorias a um termo primeiro. A relação entre esses dois livros é feita na Metafísica Z, que tematiza a substância, "que liga expressadamente as configurações da predicação - logo, as categorias - às possibilidades de equivocação da primeira categoria, a ousia”.

Com esse movimento da predicação em relação à cópula ocorre um afrouxamento dando lugar às formas exatas ou aproximativas de proporcionalidade, fazendo acontecer a homonímia pura e simples ou a equivocidade. Essa segunda ocorrência possibilita a analogia, embora Aristóteles não cite esse termo: "Era portanto capital mostrar que a tripartição homônimo, sinônimo, parônimo era sem dúvida a abertura do Tratado e, por isso mesmo, a introdução ao problema da analogia" (RICOEUR, 1988, p. 395).

Esse problema é colocado quando se pergunta se há uma possibilidade de comunidade não genérica que retire o discurso do ser da sua condição aporética. $\mathrm{O}$ conceito de analogia será evocado por Aristóteles para saber se a referência a um termo primeiro - a ousia - é ela própria uma relação pensável. Como ordem de derivação pode resultar de uma produção por reflexão a partir das condições de predicação. Daí, Aristóteles introduzir a noção matemática da analogia de proporção, conforme Ricoeur: A sua origem garante o seu estatuto científico No mesmo lance, pode compreender-se a aproximação entre a relação ad unum e a analogia de proporção como uma tentativa para alargar à relação transcendental o benefício da cientificidade que pertence a analogia de proporção. (1988, p. 403).

Observa-se que em Aristóteles o conceito de analogia não tem nada a ver com as categorias, a sua aplicação se dá devido um deslocamento de sentido que enfraquece os critérios iniciais, podendo ele unir-se à teoria das categorias. De acordo com Ricoeur, ao se penetrar na problemática do ser se encontra a analogia que transporta simultaneamente a sua conceptualidade própria, recebendo uma qualificação transcendental do campo ao qual ela se aplica. Daí o 
conceito de analogia se revestir de uma função transcendental, o que impede dele ser reconduzido à poesia, preservando-se em relação à esta e mantendo o afastamento inicial imposto pela questão: o que é o ser?

Com a abertura para a introdução da analogia no discurso filosófico um novo caso ocorrerá que é a intercepção entre vários planos do discurso segundo uma relação de iminência que é simultaneamente pensada conforme a analogia e expressa segundo a metáfora. O cruzamento da analogia com a metáfora ocorre segundo a transferência de sentido que afeta a significação dos nomes. Assim, a palavra "sábio" pode ser aplicada analogicamente a Deus e aos homens. Observa-se que não é dita de modo unívoco de Deus e dos homens, "uma vez que a significação apresenta, nos dois usos, caracteres diferentes. No homem, a sabedoria é uma perfeição "distinta"; (...). Em Deus, a sabedoria é a mesma coisa que a sua essência, a sua potência ser (...)" (RICOEUR, 1988, p. 425). Só é possível dizer do efeito metafórico da analogia quando ocorre este estilhaçar do nome e da sua significação correspondendo à uma extensão de sentido através da qual no enunciado metafórico as palavras satisfazem uma atribuição insólita em que o sentido repercute em todo o enunciado.

\section{Considerações Finais}

Assim, o adágio de Heidegger "O metafórico só existe no interior da metafísica” estabelece que a transgressão que ocorre na metáfora e na metafísica obedece ao mesmo princípio de deslocamento: transferência metafísica do sensível para o não sensível, transferência metafórica do próprio para o figurado. A metáfora usada no discurso filosófico é eficaz devido ao seu uso prever um movimento de ascendência que constitui a formação do conceito Porém, se observa que não se trata da criação do conceito empírico, mas da gênese dos primeiros filosofemas, os que articulam o campo da metafísica, como: theoria, eidos, logos, etc.

Segundo Ricoeur, Derrida desconstrói o discurso filosófico quando levanta uma suspeita universal em relação à metafísica ocidental por meio de uma suspeita mais profunda quanto à metáfora no ensaio Mythologie blanche 4 quando supõe o não - dito da própria metáfora, que é a metáfora usada. O conceito de usura, segundo o filósofo, transporta a metáfora geológica de apagamento por desgaste, de erosão. A usura traz consigo o sentido tanto de coisas usadas como, também, a usura dos usuários num paralelismo em que desmascara a

4 DERRIDA, J. Marges da la Philosophic. Paris: Ed. De Minuit., 1972. p. 247-307. 
conjunção daquilo que não foi pensado pela metafísica "dissimulada" e da metáfora "usada". Derrida parte da Estética de Hegel, que coloca que os conceitos filosóficos são significações sensíveis transpostas para a ordem espiritual, tendo como resultado uma significação abstrata própria que proporciona o apagamento metafórico da significação inicial, consequentemente o esquecimento dessa significação que de própria passa à imprópria Hegel vê nesse movimento uma inovação de sentido enquanto Derrida vê como usura da metáfora.

Esse esquema coloca em movimento para o pensamento a oposição natureza/ espírito, natureza/história, ou natureza/liberdade, ligada pela genealogia à oposição da physis à outra do mesmo corpo, a oposição sensível/espiritual, sensível/sentido (sinnlich/sinn). Em uma parte esse sistema é muito explícito em Hegel. Ora, ele descreve o espaço de possibilidade da metafísica e o conceito de metáfora assim define o seu aparecimento (DERRIDA, 1972, p. 269).

Segundo Ricoeur, a tática de Derrida consiste "em arruinar pela aporia o discurso metafísico" quando fomenta que a autodestruição da metáfora no conceito, isto é, na ideia presente a si mesma. Para Derrida, o sol é a metáfora mais insistente na filosofia por conter um traço decisivo ao possuir o "movimento que faz girar o sol na metáfora" e, por outro lado, "fazia girar a metáfora filosófica em direção ao sol". Assim, a metáfora heliotrópica é singular porque ela representa "o paradigma do sensível e da metáfora: move-se e esconde-se regularmente". Dizendo de outro modo, "o movimento do sol sempre terá sido o trajeto da metáfora":

Se o sol pode "semear", é que seu nome é inscrito no sistema de relações que o constitui. Esse nome é apenas o nome próprio de uma coisa única a qual a metáfora "servirá"; tem já começado a dizer a origem múltipla, dividida, de toda semente, o olho, a invisibilidade, a morte, o "nome próprio", etc. Se Aristóteles não se compromete com certa consequência, é sem dúvida que ela contradiz ao valor filosófico da aletheia para aparecer próprio da propriedade do sistema de conceitos que investem o filosofema "metáfora (DERRIDA, 1972, p. 291). 
A linguagem filosófica no seu processo de denominação exige a criação de significações novas devido ao seu modo de questionar que sempre se renova, daí colocar a linguagem num estado de carência semântica. A metáfora é um tropo que surge por necessidade e por extensão para preencher uma lacuna na língua por exigência de certas ideias. Então, o discurso filosófico recorre à metáfora com vistas a buscar significações pertinentes para novos aspectos da realidade por ação da inovação semântica numa tentativa de responder a questão fundante da filosofia: $O$ que é o ser?

Para responder a essa questão, além da metáfora heliotrópica, buscam-se as metáforas do solo-fundamento e da residência-retorno que são metáforas da reapropriação. Essas metáforas são em si a própria metaforicidade, sendo consideradas por Ricoeur (1988, p 439) como metáforas dominantes que asseguram a unidade epocal da metafísica porque figuram a idealização e a apropriação, "a luz e a morada figuram o próprio processo da metaforização e instauram a recorrência da metáfora sobre si mesma".

O problema da denominação é sobrevalorizado na filosofia em decorrência à oposição que se atribui ao próprio e ao figurado como sendo uma significação metafísica que pode ser dissipada por uma semântica mais precisa. O que isso quer dizer é que se acredita na ilusão de que as palavras teriam elas mesmas um sentido próprio, isto é, natural e originário Essa interpretação já foi por nós descartada. Admitimos sentido próprio como lexicalizado, ou melhor, uso corrente da palavra. Não é o prestígio da palavra que diferencia o próprio do figurado mas o seu emprego no discurso, o que caracteriza o próprio é o seu valor já lexicalizado e o metafórico é a instauração de uma nova pertinência semântica.

Recebido em: 08.11.2018 | Aprovado em: 15.04.2019

ARISTÓTELES. Poética. São Paulo: Nova Cultural, 1987. (Os Pensadores).

BENVENISTE, Émile. Problemas de Lingüística Geral II. São Paulo: Pontes, 1989.

DERRIDA, Jacques. La Mythologie Blanche. In: Marges de la Pliilosophie. Paris: Les Editions de Minuit, 1972.

GUIRAUD, Pierre. A Semântica. Rio de Janeiro: Bertrand Brasil, 1989.
SAUSSURE, Ferdinand de. Curso de Linguística Geral. São Paulo: Cultrix, 1989.

RICOEUR, Paul. Metáfora Viva. Lisboa: Rés, 1988. 